\title{
Um perfil de cargos e funções na marinha mercante luso-brasileira, séculos XVIII e XIX
}

Jaime Rodrigues

Resumo: A partir dos registros de matrículas dos marinheiros embarcados em Lisboa desde meados do século XVIII, procuro estabelecer um inventário dos cargos e das funções a bordo da marinha mercante luso-brasileira até meados do século XIX. O estudo aponta uma grande diversidade de cargos e estabelece diferenças entre dois grandes grupos: o dos oficiais e o dos marinheiros comuns. A intenção é indicar a origem nacional e étnica dos homens do mar, a fim de discutir o internacionalismo na composição das equipagens, nos termos assinalados pela historiografia.

Palavras-chave: História Marítima. História Atlântica. História Moderna. História Contemporânea. Marinheiros.

\section{Introdução}

Entre a segunda metade do século XVIII e a primeira metade do século XIX, a marinha mercante lusa e luso-brasileira contou com uma grande variedade de cargos e funções. Apresentarei, aqui, essa diversidade e, sempre que oportuno, farei um cotejamento com outras marinhas de tempos e espaços distintos.

\footnotetext{
"Professor Associado de História do Brasil e do Programa de Pós-Graduação em História do Departamento de História da Escola de Filosofia, Letras e Ciências Humanas da Universidade Federal de São Paulo. Doutor (2000) e mestre (1994) em História Social pela Universidade Estadual de Campinas. Projeto financiado pelo CNPq. E-mail: jaime.rodrigues@unifesp.br
} 
Inicialmente, é preciso distinguir os oficiais dos homens que ocupavam os postos mais baixos da marinhagem. Os primeiros tinham funções de mando; os segundos obedeciam e exerciam o trabalho braçal. Estudiosos atentaram para os confrontos que permeavam o mundo do trabalho marítimo, a saber: os contra a natureza e os entre homens hierarquicamente divididos (REDIKER, 1989; RODRIGUES, 2005; BARREIRO, 2010, p. 195).

Comecemos pelos oficiais. Na Carreira da Índia, por exemplo, o comandante da armada era o capitão-mor, aristocrata e homem de confiança do armador, situação que se transformaria na segunda metade do século XVIII, com investimentos na formação de oficiais e a possibilidade de que "[...] os lugares de comando fossem ocupados [...] por oficiais de marinha escolhidos pelas suas capacidades profissionais" (DOMINGUES, 1998, p. 20-23). Na mesma carreira, o segundo na hierarquia era o piloto, a quem "[...] competia garantir que a navegação se fazia dentro do previsto, sendo-lhe [...] necessários um conjunto de conhecimentos técnicos [...]”. Para tanto, o piloto contava com o auxílio do sota-piloto. Em seguida vinha o mestre, responsável pela supervisão das manobras do navio e pelo trabalho dos marinheiros, no que era auxiliado por contramestre e guardião (Ibid., loc. cit.).

Em fins do século XVI, os tripulantes da Carreira da Índia podiam ser divididos em três grupos: a) o pessoal de navegação, abarcando piloto, sota-piloto, mestre, contramestre, guardião, marinheiros e grumetes; b) os artesãos sem função estritamente marítima, mas fundamentais a bordo, como capelão, escrivão, meirinho, despenseiro, barbeiro, carpinteiro, calafate, tanoeiro e pagens; c) os bombardeiros, que lidavam com a artilharia (DOMINGUES, 1998, p. 22). Porém, sendo estritamente funcionais, essas categorias não levam em conta as relações de poder.

De acordo com Marcus Rediker, no século XVIII, o trabalho no mar foi padronizado: cada navio mercante levava um mestre, um imediato, um carpinteiro, um contramestre, um chefe de artilheiros, talvez um cozinheiro e quatro ou cinco marinheiros comuns. Muitos navios incluíam um segundo imediato, um imediato de carpinteiro e mais quatro ou cinco marinheiros (REDIKER, 1989, p. 83). Mesmo que o autor não o diga, essa padronização não se refere a quaisquer embarcações, mas sobretudo às britânicas. 
Ao analisar a Marinha Espanhola nos tempos modernos, Mola e Shaw optaram por dividir a gente do mar em "agentes da economia marítima”, apontando sua multiplicidade: mercadores, pescadores, marinheiros mercantes ou de guerra (MOLA; SHAW, 2007, p. 159).

As nomenclaturas que designavam funções a bordo foram muitas para o caso luso-brasileiro. Encontrei 83 designações para os cargos, as quais agruparei em blocos condizentes com as funções, referentes a 358 viagens de 302 embarcações em fontes dos anos de 1763-1799 e 1802-1863. ${ }^{1}$ Nesse caso, diferentemente das carreiras ou frotas comerciais e/ou militares, havia raros comandantes. Capitão e piloto eram os postos mais altos nessas embarcações. Em séculos anteriores, não era incomum que capitães, pilotos ou mestres fossem donos dos navios e que os dirigissem pessoalmente (PÉREZ-MALLAÍNA, 1992, p. 97-98). Mas essa não era a situação mais corriqueira nos séculos em questão: localizei 136 capitães no século XVIII e 98 no século XIX; quanto aos pilotos, a amostragem refere-se a 476 homens, eles também divididos em hierarquias mutantes entre um século e outro.

Tabela 1 - Nomenclaturas e graus de pilotos ${ }^{2}$

\begin{tabular}{c|c|c}
\hline \multirow{2}{*}{ Cargo } & \multicolumn{2}{|c}{ Século } \\
\cline { 2 - 3 } & XVIII & XIX \\
\hline Capitão & 136 & 98 \\
\hline Piloto & 112 & 92 \\
\hline Primeiro piloto & 3 & 17 \\
\hline Segundo piloto & 5 & 49 \\
\hline Terceiro piloto & 0 & 15 \\
\hline Sota-piloto & 39 & 19 \\
\hline Contrapiloto & 1 & 0 \\
\hline Praticante de piloto & 32 & 90 \\
\hline Primeiro praticante & 0 & 1 \\
\hline Segundo praticante & 0 & 1 \\
\hline
\end{tabular}

Fonte: Elaborada pelo autor. 
A partir do arrolamento das designações, ao menos uma hipótese pode ser aventada para demonstrar a dinâmica das transformações. No século XVIII, há um número ligeiramente superior de pilotos em relação ao século XIX, mas um número bem menor de primeiros, segundos e terceiros pilotos e de praticantes de pilotos. $\infty$ Com sota-pilotos e contrapilotos dá-se o contrário: foram mais comuns no século XVIII do que no XIX. A profusão de nomes deixa entrever que os navios levavam mais de um responsável pela pilotagem. É plausível que os navios que levavam mais de um encarregado pela pilotagem tenham cumprido rotas mais longas. Alguns homens foram registrados simplesmente como praticantes, e os dicionários complementam a informação omitida na fonte: "praticante é o que se distina a ser piloto, e por isso também se diz praticante de piloto” (CAMPOS, 1823, p. 86; AMORIM, 1841, p. 251).

Em todas as matrículas de capitães, a fonte não menciona cor ou condição social - evidência segura de que se tratava de homens brancos e livres. No século XVIII, 74\% dos capitães eram nascidos em Portugal; no XIX, o percentual caiu para 23,5\%. O fato de que $68,4 \%$ dos capitães desse século não tivessem sua naturalidade especificada ajuda a entender a aparente queda dos reinóis nos postos de comando, além da inclusão de navios matriculados após 1822 capitaneados por brasileiros.

Pilotar ou praticar para se tornar piloto constituía quase uma reserva de mercado para portugueses, sobretudo no século XVIII: de um universo de 191 homens nessa categoria, 156 eram portugueses de nascimento (81,6\%), sendo os demais da América portuguesa, dos Açores ou da Madeira e 15 para os quais não temos dados. No século XIX, de 284 homens nessa categoria, 176 eram portugueses (61,8\%), sendo os demais distribuídos entre nascidos no Brasil, nas ilhas atlânticas, em Macau e em países europeus. Para 57 indivíduos, não temos a informação.

No que se refere aos graus de piloto, algumas observações de caráter socialmente distintivo podem ser apontadas. Nos registros, nota-se o uso reiterado da expressão "marítimo de profissão", menos frequente quando do registro de marinheiros comuns. Eventualmente, os pilotos escreviam suas próprias matrículas, o que se percebe pela diferença da letra e da tinta. Se pensarmos na possibilidade de 
ascensão na carreira, temos ao menos um caso em que o registro menciona que o piloto fora sota-piloto em outro navio ${ }^{3}$. Também é possível ver, pela filiação, que havia praticantes filhos dos capitães dos navios em que vinham. Por vezes, isso podia criar situações de insegurança para os embarcados, como no caso do praticante de piloto João Alvares da Silva, do navio Santa Rosa e Senhor do Bonfim, que zarpou de Lisboa em junho de 1767. Ele era de um rapaz de 15 anos de idade em sua primeira viagem e, embora alegasse ter frequentado as aulas da Junta do Comércio, desconfio que sua inclusão no cargo devia-se ao fato de que ele era filho do capitão (ANTT/ JC, Livro 2 das Matrículas dos Marinheiros, 1767, fls. 22-22v).

Ainda no âmbito do oficialato, a Tabela 2 arrola outros cargos.

\section{Tabela 2 - Oficiais diversos}

\begin{tabular}{c|c|c}
\hline \multirow{2}{*}{ Cargo } & \multicolumn{2}{|c}{ Século } \\
\cline { 2 - 3 } & XVIII & XIX \\
\hline Mestre & 18 & 53 \\
\hline Contramestre & 103 & 113 \\
\hline Primeiro contramestre & 0 & 1 \\
\hline Aprendiz de contramestre & 1 & 0 \\
\hline Guardião & 2 & 9 \\
\hline Caixa & 3 & 5 \\
\hline Primeiro caixa & 1 & 0 \\
\hline Segundo caixa & 1 & 0 \\
\hline Carregador & 0 & 2 \\
\hline Sobrecarga & 1 & 12 \\
\hline Segundo sobrecarga & 0 & 1 \\
\hline Terceiro sobrecarga & 0 & 3 \\
\hline Capelão & 105 & 56 \\
\hline Cirurgião & 110 & 61 \\
\hline Escriturário & 2 & 5 \\
\hline Escrivão & 17 & 31 \\
\hline
\end{tabular}

Fonte: Elaborada pelo autor. 
Nem sempre vinham mestres a bordo, por serem melhor remunerados e porque suas tarefas poderiam ser cumpridas por um contramestre. Este sim manteve-se como cargo de presença equilibrada nos dois períodos da amostragem. O primeiro contramestre e $\mathrm{o}$ aprendiz são figuras quase inexistentes e talvez a presença deles se deva às idiossincrasias do escrevente, mais do que a um reconhecimento no trabalho marítimo. Já os guardiões, mediadores das ordens do mestre ou do contramestre aos marinheiros comuns, também foram cargos pouco frequentes, mais presentes no século XIX.

Quanto aos caixas e assemelhados (carregador e sobrecarga), eram os responsáveis pelos cuidados com as mercadorias embarcadas e a defesa dos interesses dos seus donos. Totalizaram apenas 29 homens em 358 viagens. Uma pista para explicar a pouca frequência desses cargos pode estar na constatação de que, por vezes, o capitão era quem acumulava a tarefa, sobretudo quando era sócio ou proprietário do navio e da carga transportada (FERREIRA; RIBEIRO; RODRIGUES, 2004, p. 221).

A diferença na quantidade de capelães e cirugiões pode ser explicada por especificidades do comércio e da legislação. Em 18 de março de 1684, uma lei lusa obrigava os navios do tráfico negreiro a trazerem capelão a bordo (SILVA, 1859, p. 10; RODRIGUES, 2005, p. 209). Para o século XVIII, navios mercantes que faziam comércio regular eram mais cumpridores das leis e levavam os responsáveis pelo conforto espiritual e pela saúde da tripulação, ao mesmo tempo em que autores contemporâneos destacaram que antes do reinado de D. José I não havia cirurgiões "[...] para as expedições das frotas comerciais e para o socorro das províncias, onde não havia senão barbeiros que sangravam e meros curandeiros" (ABREU, 2011, p. 122). No século XIX, muitos navios da amostragem são negreiros, sobretudo da época do contrabando, na qual as leis não eram cumpridas e não fazia sentido arcar com mais despesas num negócio cujo risco aumentava na medida em que a repressão crescia. Mesmo no comércio regular, a presença dos capelães e cirurgiões passou a ser questionada nas primeiras décadas do século XIX (CORTES, 1822, p. 1589).

Escrivães ou escriturários somaram 55 homens, com maior concentração no século XIX. Suas funções a bordo não parecem 
ter se transformado significamente no decorrer do tempo ou das mudanças técnicas nas embarcações. Tratava-se de uma espécie de oficial de cartório no mar e eram conhecedores da leitura e da escrita em um mundo de homens pouco afeitos às letras (MICELI, 1997, p. 176-178; FREITAS, 1855, p.181-182; RODRIGUES, 2005, p. 165-166).

Outro tipo de oficial mencionado nas listas de tripulantes era o despenseiro. Ele não lidava diretamente na preparação dos alimentos nem com o manejo do barco, "[...] mas sim com as vitualhas e a distribuição dos ranchos. Seu distintivo era o manejo das chaves que fechavam os paióis onde vinham os alimentos" (MOLA; SHAW, 2007, p. 161), tendo o auxílio dos pagens na tarefa de distribuição da comida. Entre suas funções, na Carreira da Índia e em outras rotas, estava a listagem do suprimento embarcado, auxiliando o (ou sendo auxiliado pelo) escrivão, e o cuidado com o armazenamento e conservação dos alimentos (DOMINGUES, 1998, p. 24; GODINHO, 2005, p. 52-53; LAPA, 1968, p. 201; CARUSO, 2010, p. 63).

\section{Ofícios de terra, ofícios do mar}

Passando àqueles que desempenhavam o trabalho braçal, começarei com os que não lidavam com os aparelhos dos navios, mas sim com a subsistência: o pessoal ligado à alimentação, com exceção do despenseiro, com grau de oficial.

\section{Tabela 3 - Pessoal de cozinha}

\begin{tabular}{c|c|c}
\hline \multirow{2}{*}{ Cargo } & \multicolumn{2}{|c}{ Século } \\
\cline { 2 - 3 } & XVIII & XIX \\
\hline Copeiro & 0 & 12 \\
\hline Ajudante de copeiro & 0 & 1 \\
\hline Cozinheiro & 44 & 66 \\
\hline Padeiro & 1 & 4 \\
\hline
\end{tabular}

Fonte: Elaborada pelo autor. 
Ao lidar com as profissões ligadas ao trabalho marítimo no Rio da Prata, Laura Caruso comenta que os homens da cozinha dos barcos “[...] eram os únicos dispensados da condição de saber nadar para serem contratados" (CARUSO, 2010, p. 63). Também está claro que eram dispensados do manejo dos instrumentos naúticos. No caso da amostra aqui analisada, os copeiros surgiram no século XIX e provavelmente prestavam serviços aos oficiais superiores. Os padeiros, em número pouco significativo, possivelmente cuidavam do suprimento de trigo e produziam pão a bordo, desde que as viagens fossem curtas ou repletas de escalas para abastecimento de lenha, o que talvez ajude a explicar sua quase ausência nas embarcações. $\mathrm{O}$ biscoito, ou pão assado duas vezes, supria a tripulação de carboidratos e deveria ser responsabilidade dos padeiros, quando estes vinham a bordo.

Quanto ao cozinheiro, era presença mais constante e "notável por sua inabilidade para cozinhar”, nas palavras de Rediker, sendo considerado inferior pelos demais por não realizar trabalho pesado (REDIKER, 1989, p. 84-85, 122). Os cozinheiros trabalhavam, na sua maior parte, para o conjunto dos embarcados. Encontrei alguns que serviam apenas ao capitão, enquanto um era servente cozinheiro e outro foi nomeado "mestre cozinheiro".

Dos 128 homens da amostragem ligados ao trabalho da cozinha, 92 eram livres e brancos, 10 eram escravos pretos e 26 eram livres ou forros pretos ou pardos. Os demais membros da tripulação eram trabalhadores braçais com funções náuticas, e dividem-se em 42 nomenclaturas. Primeiramente, vou apresentá-los e quantificá-los.

Tabela 4 - Marinheiros comuns com funções náuticas

\begin{tabular}{c|c|c}
\hline \multirow{2}{*}{ Cargo } & \multicolumn{2}{|c}{ Século } \\
\cline { 2 - 3 } & XVIII & XIX \\
\hline Tanoeiro & 14 & 18 \\
\hline Segundo tanoeiro & 0 & 6 \\
\hline Mestre tanoeiro $^{*}$ & 1 & 0 \\
\hline Oficial de tanoeiro $^{*}$ Pipeiro $^{4}$ & 1 & 0 \\
\hline Aprendiz de calafate $^{2}$ & 0 & 1 \\
\hline
\end{tabular}




\begin{tabular}{|c|c|c|}
\hline Aprendiz do mestre calafate & 2 & 0 \\
\hline Calafate & 82 & 26 \\
\hline Calafatinho & 11 & 0 \\
\hline Mestre calafate & 12 & 0 \\
\hline Oficial de calafate & 2 & 0 \\
\hline Aprendiz de mestre carpinteiro & 1 & 0 \\
\hline Aprendiz de carpinteiro & 4 & 0 \\
\hline Carpinteirinho & 5 & 0 \\
\hline Mestre carpinteiro & 5 & 0 \\
\hline Carpinteiro & 62 & 56 \\
\hline Barbeiro & 1 & $10^{5}$ \\
\hline Segundo barbeiro & 0 & 1 \\
\hline Prático & 1 & 12 \\
\hline Barraqueiro & 0 & 1 \\
\hline Boticário & 0 & 2 \\
\hline Canoeiro & 1 & 0 \\
\hline Embarcadiço & 1 & 0 \\
\hline Fiel do porão & 0 & 1 \\
\hline Franceiro (sic) & 0 & 1 \\
\hline Gajeiro da proa & 0 & 1 \\
\hline Gajeiro grande & 0 & 1 \\
\hline Grumete & $44^{6}$ & 0 \\
\hline Mancebo & $442^{7}$ & 5 \\
\hline Marinheiro & $463^{8}$ & 2381 \\
\hline Moço do navio & 15 & 0 \\
\hline Moço do governo & 15 & 0 \\
\hline Moço de viagem & 25 & 0 \\
\hline Moço do capitão & 1 & 0 \\
\hline Moço de carpinteiro & 2 & 0 \\
\hline Moço & 715 & 927 \\
\hline Oficial de pedreiro & 1 & 0 \\
\hline
\end{tabular}


Um perfil de cargos e funções na marinha mercante...

\begin{tabular}{c|c|c}
\hline Sota-sangrador & 0 & 1 \\
\hline Sangrador & 2 & 13 \\
\hline Taubário (?) & 0 & 1 \\
\hline Servente & $1759^{9}$ & 111 \\
\hline Tambor & 0 & 2 \\
\hline
\end{tabular}

Fonte: Elaborada pelo autor.

O primeiro grupo de ofícios da Tabela 4 refere-se aos responsáveis pelos líquidos embarcados. Eram responsáveis pela feitura, conserto ou conservação dos recipientes de carga: as preciosas pipas ou barris. ${ }^{10}$ Tanoeiros estiveram presentes de forma equilibrada entre os navios dos séculos XVIII e XIX, sendo que no Oitocentos aparece a novidade de um segundo tanoeiro, presente talvez em viagens para destino mais longínquo, com número maior de tripulantes ou com carga humana no porão. Ainda assim, são poucos em relação ao tamanho da amostragem (relembrando: 358 viagens, 302 embarcações), indicando que, na ausência deles, suas funções foram exercidas por outros homens: além dos carpinteiros e calafates, talvez um marinheiro comum ou um servente mais habilidoso.

Sua função especializada era absolutamente necessária para o bom andamento das viagens. Se tudo corresse bem, talvez ninguém se apercebesse dessa necessidade; caso contrário, sua falta seria muito sentida pelos demais. A amostragem permite dizer quais eram a naturalidade e a condição social desses homens.

\section{Tabela 5 - Marinheiros de ofícios de madeira}

\begin{tabular}{c|c|c|c}
\hline Ofício & Total & Proveniência & $\begin{array}{c}\text { Condição } \\
\text { Social }\end{array}$ \\
\hline & & África: 10 & \\
Tanoeiros & \multirow{2}{*}{41} & Ilhas atlânticas: 2 & Escravos: 6 \\
e assemelhados & & $\begin{array}{c}\text { Amica portuguesa/Brasil: } 6 \\
\text { Portugal: } 20\end{array}$ & $\begin{array}{c}\text { Forros: } 4 \\
\text { Livres: } 31\end{array}$ \\
& & Não identificada: 3 & \\
\hline
\end{tabular}




\begin{tabular}{|c|c|c|c|}
\hline $\begin{array}{c}\text { Calafates } \\
\text { e assemelhados }\end{array}$ & 141 & $\begin{array}{c}\text { África: } 1 \\
\text { Ilhas atlânticas: } 2 \\
\text { América portuguesa/Brasil: } 1 \\
\text { Portugal: } 112 \\
\text { Ilha de Elba: } 1 \\
\text { Não identificada: } 24\end{array}$ & $\begin{array}{c}\text { Escravos: } 2 \\
\text { Forros: } 0 \\
\text { Livres: } 139\end{array}$ \\
\hline $\begin{array}{l}\text { Carpinteiros } \\
\text { e assemelhados }\end{array}$ & 133 & $\begin{array}{c}\text { África: } 1 \\
\text { Ilhas atlânticas: } 2 \\
\text { América portuguesa/Brasil: } 3 \\
\text { Portugal: } 108 \\
\text { Espanha: } 1 \\
\text { Suécia: } 1 \\
\text { Não identificada: } 17\end{array}$ & $\begin{array}{c}\text { Escravos: } 0 \\
\text { Forros: } 0 \\
\text { Livres: } 133\end{array}$ \\
\hline
\end{tabular}

Fonte: Elaborada pelo autor.

Dentre os tanoeiros em suas diferentes denominações, os africanos provinham da Costa da Mina (exceto por um caso de Calabar), sendo 6 deles escravos e os demais forros. Os ilhéus haviam nascido nos Açores (1) ou na Madeira (1); os seis americanos eram na sua totalidade nascidos na Bahia, enquanto os 20 portugueses continentais dividiam-se entre 1 beirão, 7 do Porto ou de Braga e os outros 12 de Lisboa e seu entorno, todos eles homens livres.

Quanto aos calafates e assemelhados, o único africano da amostra era escravo e oriundo da Costa da Mina. O outro homem na condição de escravo era um natural da Ilha de Elba, território francês, cativo do piloto espanhol Victor de Barridas, tripulante do mesmo barco, o Estrela do Mar, um negreiro capturado pelos ingleses em 1828. Esses foram os únicos cativos que pude localizar nessas funções. Todos os demais calafates eram livres. Quanto aos calafates ilhéus, os dois eram da Madeira; o do Brasil vinha do Rio de Janeiro e os reinóis provinham majoritariamente do Norte (Entre-Douro e Minho, 66 homens; Lisboa e Estremadura, 44 e 2 da Beira). Desconheço as naturalidades de 24 homens. 
Fechando os ofícios da madeira, os carpinteiros e assemelhados eram todos livres. Decerto, a condição de escravo não condizia com o manuseio de objetos pontiagudos, que pudessem se tornar armas em certas situações, na visão senhorial. Isso ajuda a explicar a ausência de carpinteiros cativos, mais do que uma suposição inverossímil da inabilidade para o manejo das ferramentas e o desempenho do trabalho. Novamente, a maior parte do contingente de carpinteiro era de reinóis: eles somam 108 homens (metade do Norte, metade de Lisboa e seu entorno, subtraídos cinco beirões). $O$ único africano da amostra era caboverdiano; os dois ilhéus eram dos Açores e os três do Brasil dividiam-se entre um maranhense, um pernambucano e um baiano. Completam a lista dois estrangeiros europeus e 17 homens de proveniência ignorada.

Os dados confirmam o dizer de Russel-Wood, para quem os homens livres predominavam em certas lidas especializadas no mar. Para ele, os escravos de ganho marítimos enfrentavam dificuldades para ter acesso ao mercado de trabalho com relativa autonomia para barganhar o valor de seus serviços. Isso pelo menos em profissões como tanoeiro e calafate, que tinham "[...] menos oportunidade de trabalho que especialidades mais procuradas, como as de sapateiro, carpinteiro, pedreiro ou ferreiro" (RUSSEL-WOOD, 1991, p. 203; RUSSEL-WOOD, 2005, p. 63-64). Além do que, essas profissões também eram requisitadas em terra, nos estaleiros e na construção civil, constituindo um importante segmento do mercado de trabalho para homens livres e pobres em Portugal e no Brasil.

\section{Ofícios da saúde}

Com exceção do cirurgião, as profissões ligadas à saúde dos mareantes não faziam parte do grupo de oficiais. A amostragem traz registros sobre 28 homens, entre os quais barbeiros e sangradores foram os mais comumente encontrados a bordo, ainda assim em número reduzido diante da quantidade de viagens. Para efeito de comparação, inclui também os cirurgiões encontrados na amostra. Vejamos o que temos sobre a naturalidade e a condição social desses homens (Tabela 6). 
Tabela 6 - Marinheiros - ofícios da saúde

\begin{tabular}{|c|c|c|c|}
\hline Ofício & Total & Proveniência & $\begin{array}{c}\text { Condição } \\
\text { Social }\end{array}$ \\
\hline Cirurgião & 171 & $\begin{array}{c}\text { Portugal: } 139 \\
\text { América Portuguesa/Brasil: } 5 \\
\text { Espanha: } 3 \\
\text { Não identificada: } 23\end{array}$ & Livres: 171 \\
\hline Barbeiro & 12 & $\begin{array}{c}\text { África: } 9 \\
\text { Portugal: } 1 \\
\text { América Portuguesa/Brasil: } 1\end{array}$ & $\begin{array}{c}\text { Escravos: } 3 \\
\text { Forros: } 2 \\
\text { Livres: } 7\end{array}$ \\
\hline Boticário & 2 & $\begin{array}{l}\text { Portugal: } 1 \text { (Lisboa) } \\
\text { Não identificada: } 1\end{array}$ & Livres: 2 \\
\hline Sangrador & 16 & $\begin{array}{c}\text { África: } 11 \\
\text { América portuguesa/Brasil: } 1 \\
\text { Não identificado: } 4\end{array}$ & $\begin{array}{c}\text { Escravos: } 1 \\
\text { Forros: } 3 \\
\text { Livres: } 12\end{array}$ \\
\hline
\end{tabular}

Fonte: Elaborada pelo autor.

Se pudéssemos definir o perfil do cirurgião com base nessa amostragem, diríamos que a profissão era exercida por homens portugueses, brancos e livres. Do mesmo modo, barbeiros e sangradores eram profissões com notável presença negra, africana e escrava. Dito isso, precisaríamos ir um pouco além e entender os embates que permearam o exercício dessas profissões. Como notaram alguns autores, inúmeras embarcações e frotas zarpavam para as diferentes partes dos domínios portugueses "sem físico, cirurgião ou boticário e, às vezes sem botica”(FRADA, 1989, p. 67). João Frada, que escreveu essas palavras com base nos diários e crónicas de bordo da época dos descobrimentos, afirma ainda que o profissional da saúde mais frequente era o barbeiro, "acumulando funções de sangrador" (Ibid., loc. cit.). O inventário dos profissionais apresentado aqui, referente aos séculos XVIII e XIX, deixa claro que, nessa época, os cirurgiões eram mais numerosos. As crônicas coloniais oferecem informações preciosas, mas seguramente não são boas fontes demográficas. De todo modo, todas as fontes e interpretações confirmam que os cuidados com a saúde a bordo eram insuficientes, ainda que melhorias tenham ocorrido a partir do século XVIII (FRADA, 1989, p. 67; FRADA, 1993, p. 233). 
A presença mais incisiva dos cirurgiões pode ser entendida no contexto da luta pelo reconhecimento da profissão e das transformações do saber médico ao longo dos séculos XVIII e XIX. Medicina e cirurgia disputavam espaços de poder - a bordo dos navios, inclusive -, para demonstrar a eficácia de suas intervenções. A $\infty$ cirurgia não era reconhecida como um saber e estava mais perto de um trabalho braçal do que intelectual. Resultou que, desde o século XVII, médicos e cirurgiões separaram profundamente suas funções para fazer um movimento inverso nos Setecentos, quando

[...] o baixo nível da cirurgia [...] era prejudicial aos interesses das monarquias absolutas. Os barbeiros-cirurgiões, com instrução muito escassa, não tinham capacidade de dar respostas às exigências que pressupunha a nova organização do Exército, a navegação e os próprios hospitais (NUÑES; VILLALBA, 2012, p. 60).

Ainda de acordo com os mesmos autores e comparando os casos das armadas espanhola, francesa e inglesa, a partir de uma formação mais especializada e de uma valorização social utilitarista do trabalho manual, os cirurgiões puderam começar a superar sua notória inferioridade frente aos médicos (NUÑES; VILLALBA, 2012, p. 59-64). Em Portugal, sabemos que, na Armada, haviam sido criados dez postos de cirurgião em 1753 e que, em torno de 1770 , os oficiais dos navios de guerra eram didividos em dois escalões: o superior, composto por generais, comandantes e seus ajudantes, e o inferior, no qual constavam o capelão, o auditor, o físico e o cirurgião (CRUZ JR., 2002, p. 73-75). Mariana Candido, analisando o período entre c.1760-c.1820, constatou que a maioria dos navios levava cirurgiões a bordo: apenas 48 embarcações, de um total de 365 , não listaram esses profissionais como parte da tripulação (CANDIDO, 2010, p. 402-403).

A instrução mais escassa dos cirurgiões e seu prestígio social inferior em relação aos médicos pode ter prosseguido, a dar crédito à associação de sua nomenclatura profissional com a do barbeiro. Os navios do tráfico de escravos africanos "[...] tinham escrivão e mais raramente um cirurgião (nome que escondia um simples 
sangrador)" (CALDEIRA, 2013, p. 120; RODRIGUES, 2005, p. 272-275). A raridade do embarque de cirurgiões e barbeiros foi igualmente notada na Carreira da Índia e, mesmo quando esses profissionais vinham a bordo, pouca confiança mereciam - tanto que o Conselho da Fazenda julgou necessário escolher barbeiros mais competentes, "[...] que tenham alguma prática de cirurgia" e que entendessem da "[...] botica das mesinhas, de que usa a medicina" (RODRIGUES, 2005, p. 177; WISSENBACH, 2009, p. 281-300).

Os dicionários de marinharia também confundem as nomenclaturas, como o de Leitão e Lopes, que criaram o verbete "barbeirocirurgião" para definir o "[...] barbeiro que fazia parte da guarnição de um navio e que possuía alguns conhecimentos para tratar de feridos e certas doenças” (LEITÃO; LOPES, 1963, p. 63). Alguns conhecimentos, certas doenças: os dicionaristas não se referem ao pleno conhecimento para tratar de qualquer doença, indicando os limites da atuação dos cirurgiões e barbeiros, tidos como ofícios assemelhados.

Mais próximos entre si pareciam ser os ofícios de barbeiro e sangrador. Eles eram mencionados como sinônimos em ao menos um caso - o do preto ou crioulo (a fonte nomeia-o dos dois modos) forro Eusebio Gomes do Nascimento, com 40 anos em 1822 (AHI/ CE/CMAB, Lata 34, Maço 4, Pasta 1, navio Nova Sorte). Escravos e forros representam quase $32 \%$ da amostra (42\% dos barbeiros e $25 \%$ dos sangradores), enquanto africanos são $75 \%$ do total (75\% dos barbeiros e 69\% dos sangradores). O solitário lisboeta Joaquim da Fonseca exercia a função de barbeiro, e, infelizmente, a fonte não diz qual era sua cor. Do Brasil também vinham poucos profissionais dessa dupla: apenas dois baianos foram citados, um barbeiro e um sangrador.

Por fim, chegamos ao contingente majoritário dos trabalhadores a bordo. Chamei-os de marinheiros comuns, embora o leque também apresente diversidades na nomenclatura. Nesse grupo, reuni aqueles marinheiros que "[...] não se confundiam com os outros ofícios vinculados ao mar: carpinteiros das ribeiras, calafates, cordoeiros, tanoeiros e mergulhadores" (MOLA; SHAW, 2007, p. 160). Em outros espaços e temporalidades, como a Inglaterra de fins do século XVII e do século XVIII, diante da rebeldia dos marinheiros e da escassez de mão de obra, o Estado recrutou gente 
mais pobre e diversificada em termos étnicos para compor as tripulações (LINEBAUGH; REDIKER, 2008, p. 163). A ação de rebeldia e a incorporação de quem não podia recusar-se ao recrutamento pode estar na raiz de afirmações genéricas e ahistóricas sobre quem eram os marinheiros dos tempos modernos. Embora mal pagos e assumindo os riscos da profissão, considero exagerada e descabida a afirmação de que se tratava de uma ralé, ao menos no período e no espaço aqui tratados:

[...] a marinhagem na sua maioria era constituída por homens de extrato sócio-económico e cultural extremamente baixo, a verdadeira ralé da nossa sociedade lisboeta. Filiados à força, nos meios menos recomendados e promíscuos, ladrões recrutados no Limoeiro, vadios e mendigos, formavam as equipas dos nossos marinheiros (FRADA, 1989, p. 66-67).

Um estigma envolve essas personagens e, por vezes, o estudioso pode ser o vetor desse fenômeno. Nada nas fontes indica que o mar fosse um campo de trabalho composto em sua maioria por condenados, vadios e mendigos. Ao menos, nada indica que gente nessa situação marcasse mais presença nos ofícios marítimos do que nos terrestres, e daí proviesse o estigma. É certo que homens com essas características compunham as tripulações, mas a necessidade de experiência marítima aponta para um grupo composto por gente que sabia o que fazer em situações cotidianas a bordo, sob o risco de inviabilizar as viagens. Graças às matrículas, sabemos onde boa parte deles vivia e, sobretudo, a quanto tempo trabalhavam em embarcações mercantes. Se tinham sido vadios (com tudo o que o termo carrega de preconceito e compulsão estatal ao trabalho produtivo), mendigos (portanto, pobres) e prisioneiros (produzidos pelas práticas institucionalizadas de justiça e desigualdade no Reino e em seus domínios e pela escravidão colonial), não estavam mais nessa condição ao se engajarem nos serviços marítimos. Estamos tratando de trabalhadores, categoria que não comporta uma simples divisão binária entre o bem e o mal. 


\section{Ofícios do mar}

Diferentemente de outros tripulantes cujos ofícios especializados também eram realizados em terra, estes homens exerciam suas profissões exclusivamente no mar. Observo que as designações grumete, mancebo e servente eram comuns no século XVIII. Homens denominados simplesmente como marinheiros surgem de forma mais volumosa no século XIX, mas desconfio que o número menor no século anterior fosse compensado pela presença dos serventes, que tinham as mesmas funções mas, talvez, recebessem soldadas menores.

Vejamos o que podemos saber sobre suas proveniências e condição social.

\section{Tabela 7 - Marinheiros comuns}

\begin{tabular}{|c|c|c|c|}
\hline Ofício & Total & Proveniência & $\begin{array}{c}\text { Condição } \\
\text { Social }\end{array}$ \\
\hline Grumete & 44 & $\begin{array}{c}\text { Portugal: } 29 \\
\text { Ilhas atlânticas: } 8 \\
\text { África: } 3 \\
\text { América Portuguesa/Brasil: } 1 \\
\text { Não identificados: } 3\end{array}$ & $\begin{array}{l}\text { Livres: } 38 \\
\text { Forros: } 1 \\
\text { Escravos: } 5\end{array}$ \\
\hline Mancebo & 447 & $\begin{array}{c}\text { Portugal: } 311 \\
\text { Ilhas atlânticas: } 116 \\
\text { África: } 6 \\
\text { América Portuguesa/Brasil: } 3 \\
\text { Não identificados: } 11\end{array}$ & $\begin{array}{l}\text { Livres: } 439 \\
\text { Forros: } 2 \\
\text { Escravos: } 6\end{array}$ \\
\hline Marinheiro & 2844 & $\begin{array}{c}\text { Portugal: } 1788 \\
\text { Ilhas atlânticas: } 262 \\
\text { África: } 141 \\
\text { América Espanhola: }{ }^{11} 5 \\
\text { América Portuguesa/Brasil: } \\
135 \\
\text { Espanha: } 1 \\
\text { Ásia (Batávia): } 1 \\
\text { Não identificados: } 511\end{array}$ & $\begin{array}{c}\text { Livres: } 2756 \\
\text { Forros: } 30 \\
\text { Escravos: } 118\end{array}$ \\
\hline
\end{tabular}


Um perfil de cargos e funções na marinha mercante...

\begin{tabular}{|c|c|c|c|}
\hline MoçO $^{12}$ & 1700 & $\begin{array}{c}\text { Portugal: } 1202 \\
\text { Ilhas atlânticas: } 211 \\
\text { África: } 76 \\
\text { América Portuguesa/Brasil: } 58 \\
\text { Espanha: } 31 \\
\text { França: } 2 \\
\text { Itália: } 2 \\
\text { Ásia (Macau): } 3 \\
\text { Não identificados: } 118\end{array}$ & $\begin{array}{c}\text { Livres: } 1629 \\
\text { Forros: } 22 \\
\text { Escravos: } 49\end{array}$ \\
\hline Servente & 1870 & $\begin{array}{c}\text { Portugal: } 1181 \\
\text { Ilhas atlânticas: } 392 \\
\text { África: } 86 \\
\text { América Portuguesa/Brasil: } 43 \\
\text { América Espanhola (Mèxico): } 1 \\
\text { Malta: } 1 \\
\text { Itália: } 1 \\
\text { Não identificados: } 166\end{array}$ & $\begin{array}{c}\text { Livres: } 1691 \\
\text { Forros: } 74 \\
\text { Escravos: } 105\end{array}$ \\
\hline $\begin{array}{l}\text { Função não } \\
\text { especificada }\end{array}$ & 721 & $\begin{array}{c}\text { Portugal: } 369 \\
\text { Ilhas atlânticas: } 39 \\
\text { África: } 187 \\
\text { América Portuguesa/Brasil: } 31 \\
\text { Colômbia: } 1 \\
\text { Espanha: } 15 \\
\text { França: } 1 \\
\text { Itália: } 2 \\
\text { Ásia: } 1 \\
\text { Não identificados: } 75\end{array}$ & $\begin{array}{c}\text { Livres: } 467 \\
\text { Forros: } 37 \\
\text { Escravos: } 217\end{array}$ \\
\hline
\end{tabular}

Fonte: Elaborada pelo autor.

Um único homem foi matriculado como "grumete e mancebo", indicando que as funções e inserções eram semelhantes (ANTT/JC, Livro 2 das Matrículas dos Marinheiros, 1767, fls. 2-9). Quanto aos mancebos, um foi matriculado como "mancebo e marinheiro" e outro como "mancebo ou moço"13. Também foi registrado apenas um pardo entre os mancebos, o forro lisboeta Bento Gonçalvez (ANTT/JC, Livro 3 das Matrículas das equipagens dos navios, 17671769), sendo pretos todos os demais mancebos escravos e forros. 
Grumete, mancebo e moço são funções definidas de forma relativamente similar nos dicionários. Na hierarquia, o grumete situava-se entre marinheiro e pagem, e seu aprendizado nos mastros e "outros misteres" parecia destiná-lo ao grau de marinheiro (CAMPOS, 1823, p. 62; AMORIM, 1841, p. 177; FREITAS, 1855, p. 209), ainda que muitas vezes o destino não se cumprisse depois de anos na navegação. Há grumetes experientes e não tão jovens quanto outros embarcadiços que não subiram de posto devido ao tempo de engajamento. Falo de gente como Simão Marques, de 20 anos de idade e 4 de experiência; José Simões, de 24 anos e mais de 3 como embarcado; João Antonio, 25 anos e 4 vividos no mar; Francisco Bernardes, de 38 anos e 6 para 7 de trabalho marítimo, ou Manoel Figueira Valente, de 23 para 24 anos e 7 a 8 de tempo de embarque (ANTT/JC, Livro 2 das Matrículas dos Marinheiros, 1767). Tomando-se o universo de grumetes, mancebos, moços, marinheiros e serventes, consegui coletar informações sobre o tempo de engajamento e idade dos indivíduos no momento da matrícula, podendo precisar, assim, as idades que tinham quando se engajaram nas lidas marítimas.

Ao declararem suas idades e tempo de embarque no ato da matrícula, os homens apresentavam dados relevantes para o decorrer na viagem. Provavelmente, esse dado influía na negociação de suas soldadas e na decisão do responsável por engajá-los, se este tivesse em mente a composição de uma equipagem equilibrada entre gente experiente e novatos no trabalho marítimo. A juventude desses homens era a regra - os grumetes, por exemplo, engajavam-se, em média, aos 19 anos -, mas também chama a atenção a presença de homens mais velhos e com 15 ou 20 anos de experiência no mar sem galgar função mais elevada do que a de mancebo.

Quanto aos mancebos, as definições não são precisas em relação ao lugar deles na hierarquia. Bluteau assinalou um sentido amplo, referente à idade: mancebos eram homens de até 30 ou 40 anos, ou então moços que servem, embora sejam livres; mas ele não deixou de demarcar o sentido marítimo do termo, ao dizer que mancebos de navio se situavam entre marinheiros e serventes. Nos dicionários de marinharia que consultei, mancebo não ganhou verbete próprio, mas o termo apareceu em referência a 
"moço do governo": tanto Amorim quanto Freitas referem-se a essa função como situada entre o moço e o mancebo (BLUTEAU, 1712, v. 5, p. 280-281; AMORIM, 1841, p. 211; FREITAS, 1855, p. 212).

Em Bluteau, moço é outro termo que remete à idade e abrange "desde a adolescêcia até a varonia", aplicando-se a homens até os 40 anos ou na comparação com os mais velhos. No que se refere à condição social ou função no mundo do trabalho, moço podia ser sinônimo de criado ou servo, mas ele nada apontou quanto ao uso da palavra no mar. Já os dicionaristas de marinharia omitem o termo (como faz Campos) ou dão apenas o significado de moço de governo, como fazem Amorim e Freitas: "classe de marinheiro entre o moço e o mancebo, e que já governa o leme em tempo bonançoso" 14 .

A diversidade de nomenclaturas para moços indica diferentes funções ou diferentes oficiais a quem eles se subordinavam. Como vimos na Tabela 4, além de simplesmente serem matriculados como moços, esses homens também podiam ser do governo, do navio, de viagem, do capitão ou do carpinteiro.

Os registros de um dos moços, de dois dos serventes e de um marinheiro trazem a dimensão da cor para o universo marítimo de forma inequívoca. $\mathrm{O}$ moço pardo Domingos da Cruz, de 33 anos e 11 de atividade, declinou os nomes de seus pais e esposa e, embora não tenha assinalado o local de seu nascimento (ou o escrevente não perguntou), "declarou ser livre" (ANTT/JC, Livro 4 - Matrícula de equipagens de navios, 1767-1769). O mesmo fizeram os serventes pretos Manuel Nunes e Manuel José (ANTT/JC, Livro 4 - Matrícula de equipagens de navios, 1767-1769; ANTT/JC, Maço 1, Caixa 2) e o marinheiro da mesma cor Domingos Antonio, do negreiro Segundo, apreendido pelos ingleses em 1851 (AN/AGM, Caixa 13197, Processo 10). Desconfio que Manuel Nunes fosse um escravo fugido, embora alegasse ser livre. A hipótese baseia-se na declaração feita por ele acerca de seu local de nascimento: dizia ser natural do Arcebispado de Lima (no Peru), no Império do México (que em 1768, ano do registro, não existia). Seus conhecimentos geográficos embaralhados e sua alegação de ser um "preto livre" encontraram guarida na ignorância do escrevente, que aceitou essas informações certamente por desconhecer as minúcias territoriais dos 
vice-reinados espanhóis na América e por não desconfiar de que tamanho erro podia ser parte de uma estratégia de fuga (RODRIGUES, 2013a, p.176; RODRIGUES, 2013b, p.15). Creio, ainda, que Domingos Antonio não estivesse em fuga, mas a apreensão do palhabote onde ele servia como marinheiro por um navio de guerra britânico deu-lhe a chance de se fazer passar por livre diante dos que, naquela altura, mostravam-se como campeões da liberdade no Atlântico.

Registros dessa natureza são raros, mas somados aos milhares de outros que quase nunca apontavam a cor dos homens matriculados, indicam que cor e condição social, mais do que associados, eram quase sinônimos: brancos eram livres; pretos e pardos eram escravos (LARA, 2007, p. 135 et seq.). Lidando no interior desse consenso social, Domingos e os dois Manoeis podem ter destacado suas condições de homens livres no ato da matrícula por temerem que, na viagem que fariam a terras escravistas - os navios onde embarcaram iam de Lisboa à Paraíba, ao Grã-Pará e a Cabo Verde/ Bissau/Maranhão entre 1767 e 1770 - suas cores parda ou preta os levassem a ser confundidos propositalmente com cativos.

Fazendo as contas, temos fortes evidências de que as profissões exercidas exclusivamente no mar, como as da Tabela 7, eram ocupadas prioritariamente por portugueses livres entre a segunda metade do século XVIII e as primeiras décadas do século XIX na marinha mercante lusa e luso-brasileira. Dos 7.626 homens da amostra, 721 não tiveram suas funções específicadas; sintomaticamente, é nesse grupo que encontramos o maior número de escravos (217 indivíduos, $30 \%$ do total) e forros (37 indivíduos, $5 \%$ do total), indicando que os cativos faziam de tudo um pouco a bordo e que a condição de escravo deixava de requerer uma especialização marítima. Tratava-se de cativos que, em terra ou em mar, acompanhavam seus senhores, embarcavam como cativos de ganho ou eram propriedades dos donos da embarcação ou de oficiais.

Para muitos dos marítimos comuns, a África foi assinalada como lugar de nascimento. Além dos 491 cujo registro é explicito, atribuí outros sete em função dos etnônimos inscritos em seus nomes - gente como Imanbacaça, João Congo, Martinho Ambaca e Francisco Rebolo. 
Desde as Ordenações Filipinas, definiu-se um espaço para naturais do Reino português na navegação sob a bandeira daquele país. Na verdade, proibiram-se os marítimos lusos de se empregarem em "nenhumas navegações, nem Armadas [...] fora de nossos Reinos e Senhorios", sob pena de perderem todos os seus bens e de degredo para o Brasil por cinco anos. A justificativa era que "[...] em nossos Reinos tem bem em que ganhar suas vidas em nossas Armadas e navegações, não há razão que sendo nossos naturais, façam em outra parte as ditas navegações [...]” (CODIGO PHILIPPINO, 1870, p. 1247). A julgar pelas matrículas de equipagens aqui analisadas, a reserva de mercado em embarcações lusas para marítimos nascidos em Portugal tornou-se uma realidade até o século XIX.

\section{Considerações finais}

Autores como Scott, Rediker e Linebaugh têm abordado a história dos trabalhadores do mar desde os tempos modernos como sendo marcada pelo internacionalismo em sua composição. Rediker identificou franceses, alemães, portugueses, espanhóis, escandinavos, africanos, asiáticos e americanos a serviço da marinha inglesa, ainda que as leis fixassem em $3 / 4$ a presença obrigatória de marujos ingleses ou irlandeses. Scott observou uma grande diversidade de origens nacionais entre os marinheiros europeus que arribavam na francesa Saint-Domingue em fins do século XVIII: espanhóis, italianos, malteses e outros de diversas nacionalidades vinham ter à ilha. Esse "caldeirão de internacionalismo", na expressão de Linebaugh, era ainda mais notório nas tripulações piratas (SCOTT, 1986, p. 66; REDIKER, 1989, 2004; LINEBAUGH, 1983; LINEBAUGH e REDIKER, 2008).

$\mathrm{Na}$ marinha mercante lusa, se havia internacionalismo, ele devia-se aos africanos - aos quais os conceitos de nação e, por derivação, internacionalismo, não necessariamente coincidem com os usados pelos europeus. Para além dos reinóis, o único contingente expressivo e culturalmente diverso entre os trabalhadores na marinha mercante portuguesa era oriundo da África. Evidentemente, 
essa maior unidade não deve levar à conclusão apressada de que houve menos conflitos, laços de solidariedade e engajamento em questões de interesse de classe a bordo dos navios lusos. Esses são temas no aguardo de mais estudos.

\section{A PROFILE OF POSITIONS AND FUNCTIONS IN THE LUSO-BRAZILIAN MERCHANT MARINE, $18^{\mathrm{TH}}$ AND $19^{\mathrm{TH}}$ CENTURIES}

Abstract: From the records of registration of seamen boarded in Lisbon since mid- $18^{\text {th }}$ century, I tryed to establish an inventory of positions and functions aboard of the Luso-Brazilian merchant marine until the mid- $19^{\text {th }}$ century. The study indicates a great diversity of positions and it establishes differences between two large groups: the officers and the common sailors. The intention is to indicate the national and ethnic origin of the seamen, to discusse the internationalism in the composition of crews, as indicated in the historiography. Keywords: Maritime History. Atlantic History. Modern History. Contemporary History. Sailors.

\section{Notas}

${ }^{1}$ Ver apêndice: fontes.

${ }^{2}$ As fontes dessa e das demais tabelas do texto estão arroladas no apêndice fontes.

${ }^{3}$ Francisco Rodrigues Paiva, de 30 anos de idade e 2 de experiência marítima, que fora sota-piloto no navio Pinho, onde provavelmente tivera decepado o polegar da mão direita, conforme sua descrição física indica e, mesmo com essa deficiência adquirida, tornou-se piloto. ANTT/JC, Livro 3 - Matrículas das equipagens dos navios (1767-1769), navio N. S. da Estrela, Santa Ana e São Boaventura, zarpado de Lisboa em 15 de outubro de 1767 com destino a Pernambuco.

${ }^{4}$ Pipeiro ou pifeiro não constam em CAMPOS, 1823; AMORIM, 1841; FREITAS, 1855; MELLO, 1856.

${ }^{5}$ Sendo um deles "sangrador e barbeiro".

${ }^{6}$ Sendo um "grumete e mancebo"

${ }^{7}$ Sendo um "mancebo e marinheiro" e outro "mancebo ou moço".

${ }^{8}$ Sendo 20 deles registrados como "marinheiro ou moço" e um como "marinheiro condestável”.

"Sendo um "servente ou calafatinho" e outro "servente de cozinheiro". 
${ }^{10}$ LAPA, 1968, p. 201; DOMINGUES, 1998, p. 22. Na Armada espanhola do século XVI havia a "[...] figura muito peculiar do 'alguacil [xerife] del agua', encarregado especificamente de que as rações desse líquido vital chegassem a todos os membros da tripulação sem as perdas ocasionadas por roubos"”, (PÉREZ-MALLAÍNA, 1992, p. 99-100).

${ }^{11}$ Um de Cuba, um do Chile, um de Montevidéu, um de Porto Rico e outro designado apenas como "americano".

${ }^{12}$ Inclui as seguintes nomenclaturas: "moço do navio", "moço do governo", "moço de viagem", "moço do capitão" e "moço de carpinteiro".

${ }^{13}$ José Francisco e Antonio Fernandes Braga, respectivamente. ANTT/JC, Livro 2 das Matrículas dos Marinheiros, 1767, fls. 10-21v e 66-66v e Livro 5 das Matrículas das Equipagens dos Navios, 1767-1769.

${ }^{14}$ BLUTEAU, 1712, v.5, p. 524-525; CAMPOS, 1823; AMORIM, 1841, p.211; FREITAS, 1855, p.212. Os dicionários de Amorim e o de Freitas têm inúmeros verbetes literalmente iguais, por vezes fazendo coincidir, ou quase, os números de páginas.

\section{Referências}

“Cortes - Sessão 460 - 9 de setembro [de 1822]”. Diário do Governo, Lisboa, n. 213. ABREU, Jean Luiz Neves. Nos domínios do corpo: o saber médico luso-brasileiro no século XVIII. Rio de Janeiro: Editora Fiocruz, 2011.

AFONSO MOLA, Marina; SHAW, Carlos Martínez. Los trabajos y los días del marinero del Antiguo Régimen. In: JIMÉNEZ, Francisco Chacón; FRANCO, Juan Hernández (Ed.). Espacios sociales, universos familiares: La familia en la historiografía española. Murcia: Universidad de Murcia, 2007.

AMORIM, João Pedro. Dicionário da Marinha. Lisboa: Imprensa Nacional, 1841.

BARREIRO, José Carlos. A formação da força de trabalho marítima no Brasil: cultura e cotidiano, tradição e resistência (1808-1850). Tempo, Rio de Janeiro, v. 15, n. 29, p. 189-209, jul./dez. 2010.

BLUTEAU, Raphael. Vocabulario portuguez \& latino. Coimbra: Collegio das Artes da Companhia de Jesu, 1712.

CALDEIRA, Arlindo Manuel. Escravos e traficantes no império português. Lisboa: A Esfera dos Livros, 2013. 
CAMPOS, Maurício da Costa. Vocabulário marujo: ou conhecimento de todos os cabos necessários ao navio; do seu poliame e de todos os termos marujaes, e de alguns da construção naval e artilheria; de indispensável conhecimento do oficial do mar. Rio de Janeiro: Of. de Silva Porto, 1823.

CANDIDO, Mariana P. Different Slave Journeys: Enslaved African Seamen on Board of Portuguese Ships, c. 1760-1820s. Slavery and Abolition, v. 31, n. 3, p. 395-409, 2010.

CARUSO, Laura Gabriela. Onde manda capitão, não governa marinheiro? O trabalho marítimo no rio da Prata, 1890-1920. Mundos do Trabalho, Florianópolis, v. 2, n. 3, jan./jul. 2010.

Codigo Philippino ou Ordenações e Leis do Reino de Portugal, recopiladas por mandado d'El Rey D. Philippe I. Rio de Janeiro: Typ. do Instituto Philomatico, 1870.

CRUZ JR., A. O mundo marítimo português na segunda metade do século XVIII (ensaio). Lisboa: Edições Culturais da Marinha, 2002.

DOMINGUES, Francisco Contente. A Carreira da Índia. Lisboa: [s. n.], 1998. FERREIRA, Sérgio C.; RIBEIRO, Joana Isabel; RODRIGUES, Pedro G. Episódios do comércio marítimo portuense na segunda metade do século XVIII. História: Revista da Faculdade de Letras da Universidade do Porto, Porto, v. 5, série 3, p. 211-250, 2004.

FRADA, João José Cúcio. A alimentação a bordo das naus na época moderna. In: SOARES, Virgílio Meira et al. A Universidade e os descobrimentos. Lisboa: CNPCDP; Imprensa Nacional; Casa da Moeda, 1993.

n. 18, 1989.

. História, medicina e descobrimentos portugueses. Revista ICALP, Lisboa,

FREITAS, Antonio Gregório de. Novo dicionário de marinha de guerra e mercante. Lisboa: Imprensa Silviana, 1855.

GODINHO, Rui Landeiro. A Carreira da Índia: aspectos e problemas da tornaviagem (1550-1649). Lisboa: Fundação Oriente, 2005.

LAPA, José Roberto do Amaral. A Bahia e a Carreira da Índia. São Paulo: Cia. Editora Nacional; Edusp, 1968.

LARA, Silvia H. Fragmentos setecentistas: escravidão, cultura e poder na América portuguesa. São Paulo: Cia. das Letras, 2007. 
LEITÃO, Humberto; LOPES, José Vicente. Dicionário da linguagem de marinha antiga e atual. Lisboa: Centro de Estudos Históricos Ultramarinos, 1963.

LINEBAUGH, Peter; REDIKER, Marcus. A hidra de muitas cabeças: marinheiros, plebeus e a história oculta do Atlântico revolucionário. São Paulo: Cia. das Letras, 2008.

. Todas as montanhas atlânticas estremeceram. Revista Brasileira de História, São Paulo, n. 6, set. 1983.

MELLO, João de Fontes Pereira de. Tratado pratico do aparelho dos navios para uso dos alunos da Companhia e Real Academia dos Guardas Marinha. 2. ed. Lisboa: Tip. de Mesma Academia, 1856.

MICELI, Paulo. $O$ ponto onde estamos: viagens e viajantes na história da expansão e da conquista (Portugal, séculos XV e XVI). 2. ed. Campinas: Editora da Unicamp, 1997.

NUÑES, Marcelo Frías; VILLALBA, Peça Hernandéz. La sanidad y los espacios marítimos: entre la Ilustración y la España liberal. In: HURTADO, Manuel -Reyes García (Ed.). La Armada española en el siglo XVIII: ciencia, hombres y barcos. Madrid: Síliex, 2012.

PÉREZ-MALLAÍNA, Pablo E. Los hombres del océano: vida cotidiana de los tripulantes de las flotas de Indias, siglo XVI. Sevilha: Servicio de Publicaciones de la Diputación de Sevilla, 1992.

REDIKER, Marcus. Between the Devil and the Deep Blue Sea: Merchant Seamen, Pirates, and the Anglo-American Maritime World (1700-1750). Nova Iorque: Cambridge University Press, 1989.

. Villains of All Nations: Atlantic Pirates in the Golden Age. Boston: Beacon Press, 2004.

RODRIGUES, Jaime. Escravos, senhores e vida marítima no Atlântico: Portugal, África e América portuguesa, c.1760-c.1825. Almanack, Guarulhos, n. 5, p. 145-177, maio 2013a.

. Marinheiros forros e escravos em Portugal e na América Portuguesa (c. 1760-c. 1825). Revista de História Comparada, Rio de Janeiro, v. 7, n. 1, p. 9-25, jul. 2013b.

. De costa a costa: escravos, marinheiros e intermediários do tráfico negreiro de Angola ao Rio de Janeiro (1780-1860). São Paulo: Cia. das Letras, 2005. 
RUSSEL-WOOD, A. J. R. Ports of Colonial Brazil. In: KNIGHT, Franklin W. Atlantic Port Cities: Economy, Culture, and Society in the Atlantic World (1650-1850). Knoxville: The University of Tennessee Press, 1991.

. Escravos e libertos no Brasil colonial. Rio de Janeiro: Civilização Brasileira, 2005.

SCOTT, Julius Sherrard. The Common Wind: Currents of Afro-American Communication in the Era of the Haitian Revolution. Ann Arbor: Duke University, 1986.

SILVA, José Justino de Andrade e. Collecção Chronológica da Legislação Portugueza, compilada e annotada por José Justino de Andrade e Silva (1683-1700). Lisboa: Imprensa Nacional, 1859.

WISSENBACH, Maria Cristina C. Cirurgiões e mercadores nas dinâmicas do comércio atlântico de escravos. In: SOUZA, Laura de Mello; FURTADO, Junia Ferreira; BICALHO, Maria Fernanda (Org.). O governo dos povos. São Paulo: Alameda, 2009. 
Um perfil de cargos e funções na marinha mercante...

\section{Apêndice:}

\section{Fontes}

\begin{tabular}{|c|c|}
\hline \multicolumn{2}{|c|}{ Abreviaturas } \\
\hline AN $=$ & AGM = Auditoria Geral de Marinha \\
Arquivo Nacional & JC = Junta do Comércio \\
AHI = & IGP = Intendência Geral de Polícia \\
Arquivo Histórico & CMAB = Comissão Mista Anglo Brasileira (RJ) \\
do Itamaraty & $\mathrm{CE}=$ Coleções Especiais \\
ANTT = & L = Lata \\
Arquivos Nacionais/ & $\mathrm{M}=$ Maço \\
Torre do Tombo & $\mathrm{P}=$ Pasta \\
& $\mathrm{C}=$ Caixa \\
\hline
\end{tabular}

\begin{tabular}{|c|c|}
\hline Arquivo & Fundo e cota \\
\hline AN & AGM, C. 13.195, Processos 2 e 4 \\
\hline AN & AGM, C. 13.196, Processo 6 \\
\hline AN & AGM, C. 13.197, Processos 14 e 15 \\
\hline AN & AGM C. 13.198, Processos 20 e 21 \\
\hline AN & JC, C. 445, Pacote 2 \\
\hline AN & JC, Códice 416, v. 1 \\
\hline AHI & CE, CMAB, L. 1, M. 1, P 1 \\
\hline AHI & CE, CMAB, L. 2, M. 2 \\
\hline AHI & CE, CMAB, L. 3, M. 4, P 1 e L. 3, M. 5, P 1 \\
\hline AHI & CE, CMAB, L. 4, M. 4, P 1 \\
\hline AHI & CE, CMAB, L. 5, M. 4, P 1 \\
\hline AHI & CE, CMAB, L. 6, M. 1, P 1 \\
\hline AHI & CE, CMAB, L. 7, M. 5, P 1 \\
\hline
\end{tabular}


Jaime Rodrigues

\begin{tabular}{|c|c|}
\hline $\mathrm{AHI}$ & CE, CMAB, L. 8, M. 6, P 1 \\
\hline AHI & $\begin{array}{c}\text { CE, CMAB, L. 10, M. 1, M. 2; L. 10, M. 1, P 1; L. 10, } \\
\text { M. 4, P } 1\end{array}$ \\
\hline AHI & CE, CMAB, L. 12, M. 4, P 1 \\
\hline AHI & CE, CMAB, L. 13, M. 2; L. 13, M.s 1, 1A e 1B \\
\hline $\mathrm{AHI}$ & CE, CMAB, L. 14, M. 3, P 1; L. 14, M. 4, P 1 \\
\hline AHI & CE, CMAB, L. 15, M. 1, P 1, L. 15, M. 4, P 1 \\
\hline AHI & CE, CMAB, L. 16, M. 2, P 3; L. 16, M. 4, P 2 \\
\hline AHI & CE, CMAB, L. 17, M. 4, P 1 \\
\hline AHI & CE, CMAB, L. 18, M. 1; L. 18, M. 3, P 1; L. 18, M. 4 \\
\hline AHI & CE, CMAB, L. 19, M. 2, P 1; L. 19, M. 3, P 2 \\
\hline AHI & CE, CMAB, L. 20, M. 1, P 1; L. 20, M. 3 \\
\hline AHI & CE, CMAB, L. 21, M. 2, P 1; L. 21, M. 7, P 1 \\
\hline AHI & $\begin{array}{l}\text { CE, CMAB, L. 23, M. 1, P 1; L. 23, M. 2, P 1; L. 23, } \\
\text { M. 3, P } 1\end{array}$ \\
\hline AHI & CE, CMAB, L. 24, M. 2 \\
\hline AHI & CE, CMAB, L. 25, M. 2; L. 25, M. 4, P 1 \\
\hline AHI & $\begin{array}{l}\text { CE, CMAB, L. 26, M.1, P 1; L. 26, M. 3; L. 26, M. 4, } \\
\text { P 1; L. 26, M. 6, P 1; L. 26, M. 6, P } 2\end{array}$ \\
\hline AHI & CE, CMAB, L. 27, M. 1, P 1, L. 27, M. 3, P 1p \\
\hline AHI & CE, CMAB, L. 28, M. 2, P 2 \\
\hline AHI & $\begin{array}{c}\text { CE, CMAB, L. 30, M. 1, P 1; L. 30, M. 3; L. 30, M. 4, } \\
\text { P 1; L. 30, M. 5; L. 30, M. 7, P } 1\end{array}$ \\
\hline AHI & $\begin{array}{l}\text { CE, CMAB, L. 31, M. 3; L. 31, M. 4, P 1; } \\
\text { L. 31, M. 6, P } 1\end{array}$ \\
\hline AHI & CE, CMAB, L. 34, M. 4, P 1 e 1 \\
\hline ANTT & $\begin{array}{l}\text { IGP - Contas para a Secretaria, desde } 15 \text { de junho } \\
\text { de } 1780 \text { até } 11 \text { de agosto de } 1783 \text {, Livro } 1\end{array}$ \\
\hline
\end{tabular}


Um perfil de cargos e funções na marinha mercante...

\begin{tabular}{|c|c|}
\hline ANTT & $\begin{array}{l}\text { IGP - Contas para as Secretarias, desde } 13 \text { de agosto } \\
\text { de } 1783 \text { até } 29 \text { de setembro de } 1787 \text {, Livro } 2\end{array}$ \\
\hline ANTT & $\begin{array}{l}\text { IGP - Contas para as Secretarias, desde o } 1^{\underline{a}} \\
\text { de outubro de } 1787 \text { até } 15 \text { de janeiro de } 1793 \text {, Livro } 3\end{array}$ \\
\hline ANTT & JC, Livros $1,2,3$, 4 e 5 \\
\hline ANTT & JC, M. 34, C. 112, 113, 114, 115 e 116 \\
\hline ANTT & JC, M. 37, C. 128 \\
\hline ANTT & JC, M. 62, C. 203 e 204 \\
\hline ANTT & $\begin{array}{l}\text { JC - Avisos, consultas e outros documentos relativos } \\
\text { aos cabedais vindos nas frotas do Brasil, M. 49, C. } 164\end{array}$ \\
\hline ANTT & $\begin{array}{c}\text { JC - Relações de equipagens de navios e passageiros, } \\
\text { M. } 1, \text { C. } 1,2,3,5,6,7 \text { e } 8\end{array}$ \\
\hline
\end{tabular}

Recebido em: 18/10/2014

Aprovado em: 15/01/2015 